\section{Simple depressed skull fracture causing posterior third superior sagittal sinus occlusion and elevated intracranial pressure}

\begin{abstract}
Sir,
Majority of depressed fractures are treated conservatively for the fear of bleeding from venous sinuses, but surgical intervention is indicated in some patients. ${ }^{[1-4]}$ Elevated intracranial pressure secondary to depressed skull fracture on the posterior part of the superior sagittal sinus (SSS) is rare ${ }^{[2]}$ and may account for clinical deterioration. We present one such patient and review the relevant literature.
\end{abstract}

A 6-year-old boy presented with history of road traffic accident. At the time of admission he was conscious, obeying commands, and moving all four limbs equally. There was no external wound on the scalp. Computerized tomography (CT) scan showed midline depressed fracture in the posterior parietal region without any parenchymal injury or hematoma. He deteriorated gradually over the next three days, unresponsive to commands with flexor motor response (GCS score 8). There were no lateralizing neurological deficits. Repeat CT scan revealed no changes as compared to the previous CT scan. Magnetic resonance (MR) venography showed occlusion of superior sagittal sinus (SSS) due to overlying depressed fracture [Figure1]. Elevation of depressed fracture was done. There was no tear of SSS. The patient showed gradual improvement over the next few days. Repeat MR venography showed no occlusion of SSS [Figure 2]. He was discharged on seventh postoperativeday.

It is a common neurosurgical wisdom that depressed cranial fractures over the SSS should not be elevated because of the risk of fatal venous hemorrhage. The surgical management of depressed skull fractures is indicated when a venous sinus is occluded by the depressed fracture resulting in elevated intracranial pressure. ${ }^{[1-4]}$ Successful treatment of elevated intracranial pressure in patients with depressed fracture and SSS thrombosis by conservative treatment (repeated lumbar punctures, oral acetazolamide, and anticoagulation) has been described. Probably this approach may not be appropriate in patients with altered mental status. Spontaneous recanalization of the SSS has been described. ${ }^{[5]}$ A small tear in the SSS can be treated by headend elevation and compressing the SSS with Gelfoam. ${ }^{[1]}$ Smooth depression can carefully be elevated without

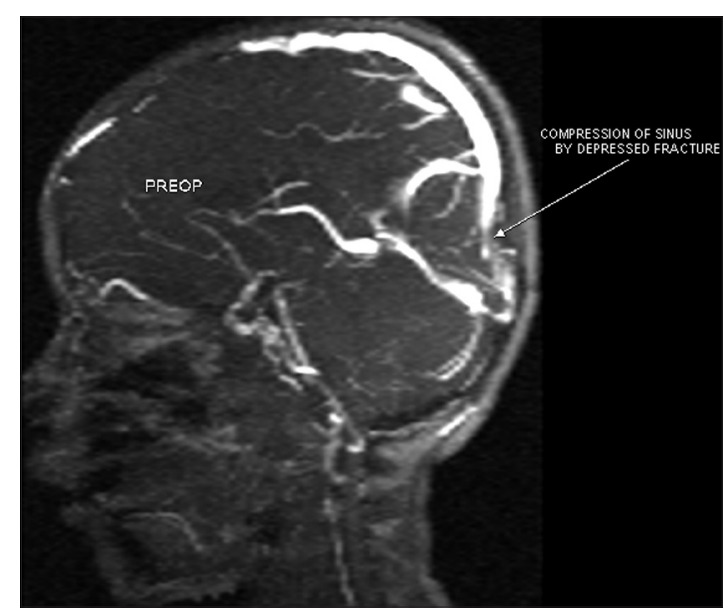

Figure 1: Preoperative two-dimensional time of flight mid-sagittal maximum intensity projection image of magnetic resonance venography showing compression and anterior displacement of posterior superior sagittal sinus

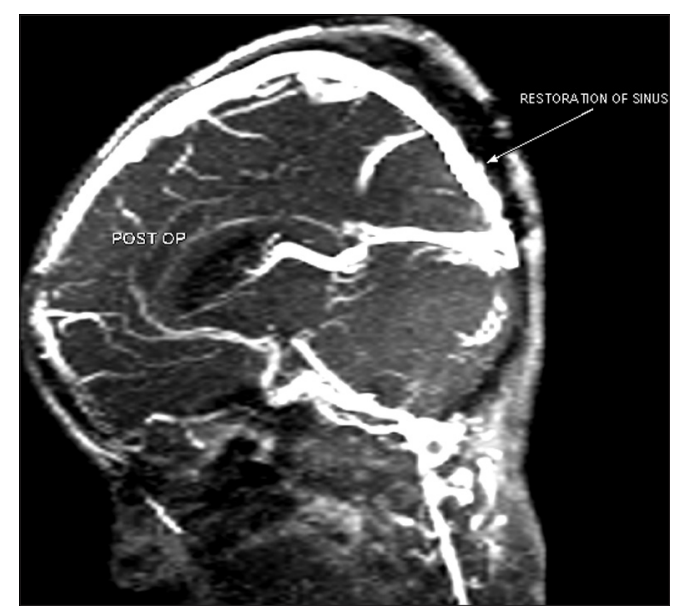

Figure 2: Postoperative two-dimensional time of flight mid-sagittal maximum intensity projection image of magnetic resonance venography showing repositioning and restoration of normal flow of posterior superior sagittal sinus

any significant bleeding. Depressed fracture with sharp bony spicule overlying major sinus can result in major bleeding from sinuses, ${ }^{[3]}$ which can be treated by headend elevation and compression by Gelfoam. Stay sutures should be used to hold Gelfoam compressed against venous sinuses. Sinus repair may be required in these cases. There are reports of delayed surgery for repair of open depressed skull fractures in order to maximize medical management in the setting of acute trauma. This delay can also avoid the risk of intraoperative elevation of intracranial pressure occurring, which at times, can be very acute. ${ }^{[4]}$ There are reports of successful surgical treatment of elevated intracranial pressure in patients with depressed skull fractures over the SSS. ${ }^{[2]}$ High preoperative elevated intracranial pressure may decline immediately after elevation of the depressed fracture with good recovery. ${ }^{[2]}$ 


\section{Y. R. Yadav, Vijay Parihar, Mallika Sinha,} Nishin Jain ${ }^{1}$

Department of Neurosurgery, Apex Hospital, ${ }^{1} M P$ MRI and CT Scan Centre, Jabalpur, MP 482 003, India. E-mail: yadavyr@yahoo.co.in

DOI: $10.4103 / 0028-3886.59500$

\section{References}

1. Tanaka H, Tanaka H, Kobata H. Superior sagittal sinus occlusion caused by a compound depressed skull fracture: A case treated by emergency surgery. No Shinkei Geka 2004;32:753-8.

2. Fuentes S, Metellus P, Levrier O, Adetchessi T, Dufour H, Grisoli F. Depressed skull fracture overlying the superior sagittal sinus causing benign intracranial hypertension. Description of two cases and review of the literature. Br J Neurosurg 2005;19:438-42.

3. Ozer FD, Yurt A, Sucu HK, Tektaş S. Depressed fractures over cranial venous sinus. J Emerg Med 2005;29:137-9.

4. Curry DJ, Frim DM. Delayed repair of open depressed skull fracture. Pediatr Neurosurg 1999;31:294-7.

5. Tamimi A, Abu-Elrub M, Shudifat A, Saleh Q, Kharazi K, Tamimi I. Superior sagittal sinus thrombosis associated with raised intracranial pressure in closed head injury with depressed skull fracture. Pediatr Neurosurg 2005;41:237-40.

Accepted on 19-03-2009 